\title{
Residential Environment and Types of Childhood
}

\author{
Baldo Blinkert ${ }^{1}$, Ellen Weaver ${ }^{2}$ \\ ${ }^{1}$ Institut für Soziologie, Albert Ludwigs Universität, ('Sociology Institute, Albert Ludwigs University'), Freiburg, Germany \\ ${ }^{2}$ Freiburger Institut für angewandte Sozialwissenschaft, (FIFAS)('Freiburg Institute for Applied Sociology'), Freiburg, Germany
}

\section{Email address:}

baldo.blinkert@soziologie.uni-freiburg.de (B. Blinkert), ellenweaver@gn.apc.org (E. Weaver)

\section{To cite this article:}

Baldo Blinkert, Ellen Weaver. Residential Environment and Types of Childhood. Humanities and Social Sciences.

Vol. 3, No. 5, 2015, pp. 159-168. doi: 10.11648/j.hss.20150305.11

\begin{abstract}
Children who are not enabled to play freely may suffer limitations in their physical, social and cognitive development. There is a danger that widespread play deprivation may lead to future generations of adults lacking essential social and personal skills. Recent German research identifies opportunities for children aged between 5 and 9 to begin experiencing independence as essential for healthy child development, and distinguishes between autonomous and heteronomous forms of childhood. The amount of time that children in this age group play outside without adult supervision was investigated and found to correlate with the quality of children's residential environments. The quality of the 'action space' available to children correlates with the economic and cultural resources of their families, so that children from socially and materially deprived homes have significantly less opportunity to develop their autonomy, through the 'latent curriculum' of free play, than children from more affluent homes: 'street childhood' has become a sign of wealth rather than poverty. Conventional playgrounds with limited, fixed installations lack scope for imaginative or creative play and fail to meet the requirements of quality play space for children. In contrast, action spaces designed with local children and which allow for creative play with natural materials are $50 \%$ cheaper to build than standard playgrounds. The need is asserted for children's policy to be embedded in housing, public space, traffic and urban design decisions, in order for the right to play to be effectively implemented. These developments are contrasted with the prevailing culture and controversies on child safety and freedom in the USA, and compared to current trends and debates in the UK on the changing nature of childhood, restricted play opportunities and child safety. The impact of UK law is considered as a key factor contributing to fear of allowing children to experience risk in play. Further research is proposed to investigate the potential for urban design to enable healthier city childhoods, the relevance of common law as distinct from civil law systems in impairing exercise of the right to play, and the impact of cultural patterns on children's opportunities to develop autonomy.
\end{abstract}

Keywords: Children, Autonomous Childhood, Residential Environment, Outdoor Play, Risk, Law, Germany, UK

\section{Introduction}

Children who are not enabled to play freely may suffer profound and long term limitations in their physical, social and cognitive capacities. A society in which children are deprived of adequate play is failing to meet a basic component of these children's health and care needs. Children's freedom to play outside and without adult interference has diminished drastically in many western, industrialised societies. This trend towards play deprivation is not only an urgent children's rights and health issue, but may also have alarming, long term social consequences, since there is a danger that, as a result, future generations of adults will be unable to fulfil their potential and may lack essential skills with which to participate effectively in society.

This article describes the purpose and methodology of a study recently conducted in South West Germany entitled Raum für
Kinderspiel! (Space for children to play!), which examined the play experiences, residential areas and family circumstances of over 5,000 children aged between 5 and 9 years old. 1

The central findings of this research are summarised, demonstrating that the quality of the space around their homes is the key factor affecting the amount of time that children play outside without adult supervision. The study exposes family resources and social status as correlating with the quality of children's space to play outside; the social and material deprivation suffered by children in under-resourced families, is compounded by their lack of access to suitable places in which to develop their autonomy and in which to benefit from the 'latent curriculum' of free play.

1 Baldo Blinkert, Peter Höfflin, Alexandra Schmider, Jürgen Spiegel: Raum für Kinderspiel!, Berlin (LIT-Verlag) 2014 
Recommended responses are proposed to redress this inequality in access to suitable space for free play, focussing in particular on the demonstrated benefits of low cost options, and the need is asserted for children's policy to be imbedded in housing, public space and urban design decisions.

The international significance of this research is considered, with particular reference to those countries where public and policy debates are raging on the recent drastic changes in the nature of childhood, the problems of over-protected children and the growth of a risk averse society. Legal, social and cultural differences are examined to identify the extent to which these findings can and should influence public policy.

Recommendations are made for further research and conclusions are set out on the significance of these research findings.

\section{Context}

There is cogent evidence that free play is essential to healthy child development. 2 While indoor, physically passive and individual play have beneficial roles, there is a primary and fundamental need for play between children of similar ages for basic socialisation, as well as for play which allows children to stretch their physical boundaries. Schooling, structured sports and indoor activities may meet some of these requirements, but optimal child development necessitates opportunities for children to interact with each other freely using their imaginations and creativity.

In order to progress towards autonomy, children also need spaces where they can test and develop their skills without adult interference. This includes the necessity for opportunities to learn risk taking skills. Play deprivation impairs the growth of self confidence and prevents children from gaining basic social and physical competences, particularly in risk-taking. 3

The importance of play to children's intrinsic wellbeing and to their healthy development has been recognised in Article 31 of the United Nations Convention on the Rights of the Child ('UNCRC'), which enshrines the right to play in international law.4 In February 2013 the UN Committee on the Rights of the Child issued a General Comment on 'the right of the child to rest, leisure, play, recreational activities, cultural life and the arts', emphasising the obligations on Signatory States to ensure effective implementation of the right to play. 5

Children who lack opportunities to play freely out of doors suffer considerably more psychological, emotional, and

2 There is a vast literature on this topic in both English and in German e.g. Zinnecker, J. Zeiher, H. 1990, 1990, Hüttenmoser, M. Degen-Zimmermann D. 1997, Graf, C. Dordel S. Koch B. Predel H-G. 2006, Olk, Th; Hübenthal, M. 2011 Renz-Polster, H. Hüther G. 2013; Relevant literature reviews in English include Play England 2011, Brussoni et al. 2012, Gleave 2008, Rogers et al 2009, Tremblay et al. 2015.

3 Supra Footnote 2.

4 UN General Assembly, Convention on the Rights of the Child, 1989, United Nations, Treaty Series, vol. 1577, p. 3. South Sudan and the USA are the only two UN Member States which have not ratified the UNCRC.

5 UN Committee on the Rights of the Child (CRC), General comment No. 17 (2013) (art. 31), 17 April 2013, CRC/C/GC/17. medical problems, 6 as well as stunted relationships to nature.7 This is the context in which the research study Raum für Kinderspiel! ('Space for children to play!') was commissioned by the Deutsches Kinderhilfswerk 8 and conducted by Freiburger Institut für angewandte Sozialwissenschaft 9 and the Evangelischen Hochschule, 10 Ludwigsburg, in order to identify the conditions which enable or impede children's opportunities to play freely, without adult supervision, out of doors.

\section{Raum für Kinderspiel! - 'Space for Children to Play'! - Purpose and Methodology}

The research team which designed and conducted Raum für Kinderspiel! took as their starting point the view that children between the ages of 5 and 9 (inclusive) have a developmental need to play freely, out of doors, without adult supervision, in order to acquire essential skills with which they can move towards autonomy. It is at this stage in children's lives that they should gradually start to loosen their ties to their parents and their immediate home environment, as their own individual experiences and developing interests take on increasing significance. Children who have these kinds of opportunities have the chance to experience not only stimulation and excitement, but also to develop their self confidence, learn their own boundaries and abilities, and acquire competence in dealing with risks.

The researchers assert that the learning which is essential to healthy childhoods takes place not only in school, but also through free play. While considerable emphasis is placed on measuring and comparing school systems, little attention has been paid to assessing the quality of free play opportunities available to children, although these are essential for them to fulfil the vital 'latent curriculum' through play.

The research project was undertaken in five local authorities of Baden Württemberg, South West Germany in 2013.11 The investigation used several research methods: Surveys were conducted with parents who have children aged 5 to 9 years old. Parents were asked to complete structured diaries on the activities of these children on 3 weekdays. Information was collected by observations of the outdoor environment in the areas where these children live. The researchers recorded children's comments and opinions about their environments, as they walked through their neighbourhoods with them. These methods produced data on about 5,000 children, which could be classified in terms of their outdoor environments and their afterschool activities. This enabled the researchers to demonstrate how children's different daily routines are connected with, and influenced by, environmental conditions. 12

6 Supra Footnote 2.

7 For example Louv 2008; Moss 2012, Thomas and Thompson 2004.

8 DKHW: German Children's Aid Organisation.

9 FIFAS: Freiburg Institute for Applied Sociology.

10 Protestant University.

11 Ludwigsburg, Offenburg, Pforzheim, Schwäbisch Hall and Sindelfingen.

12 Blinkert et al. 2014, pages 53 - 54. 
The central explanatory variable in this research has been defined as "quality of action space". An "action space" is a territory outside the home with the following attributes:

- it should be relatively free of danger,

- be accessible for children,

- have a utility value according to the interests and needs of children, and

- must offer opportunities for interaction with other children.

The extent to which the children's environments had these properties was assessed on three sets of information:

1. A list of attributes which describe the objective conditions of the area (as per table below).

2. Assessments given by parents on the physical conditions in the neighbourhood

3. Parents' evaluations of the social climate of the neighbourhood, e.g. how many other children's names do they know; how probable is it that a child would get help if they had a problem while outside on their own.

Table 1. Criteria for the assessment of action space quality ("Freiburger Sociotopen Test") (Blinkert 1993).

\begin{tabular}{|c|c|c|c|}
\hline & \multicolumn{3}{|l|}{ Indicators for... } \\
\hline & good quality & medium & bad quality \\
\hline \multirow{3}{*}{ type of domicile } & owner occupier & & rented \\
\hline & ground floor & 1st storey, 2nd storey & higher \\
\hline & one family & & multiple families \\
\hline \multirow{4}{*}{$\begin{array}{l}\text { area near the home } \\
\text { ( } 50 \mathrm{~m} \text { zone) }\end{array}$} & garden or backyard & & no garden/backyard \\
\hline & front garden usable & front garden not usable & no front garden \\
\hline & space in front of building & & no space in front of building \\
\hline & distance from entrance to street more than 30 metres & distance 5 to $30 \mathrm{~m}$ & distance less than $5 \mathrm{~m}$ \\
\hline \multirow{4}{*}{$200 \mathrm{~m}$ zone } & play street (limited vehicle access) & Traffic speed limit $30 \mathrm{~km} / \mathrm{h}$ & more than $30 \mathrm{~km} / \mathrm{h}$ \\
\hline & not on a street & street less than 6 metres wide & street over 6 metres wide \\
\hline & low noise levels & medium noise levels & high noise levels \\
\hline & 3 or fewer parked cars & 4 to 9 parked cars & 10 or more parked cars \\
\hline \multirow{4}{*}{$500 \mathrm{~m}$ zone } & no busy streets & & busy streets \\
\hline & purely residential area & mixed area & industrial area \\
\hline & natural areas (park, water) & & no natural areas \\
\hline & large playground/football pitch & & no large playground/football pitch \\
\hline
\end{tabular}

\section{Key Research Findings}

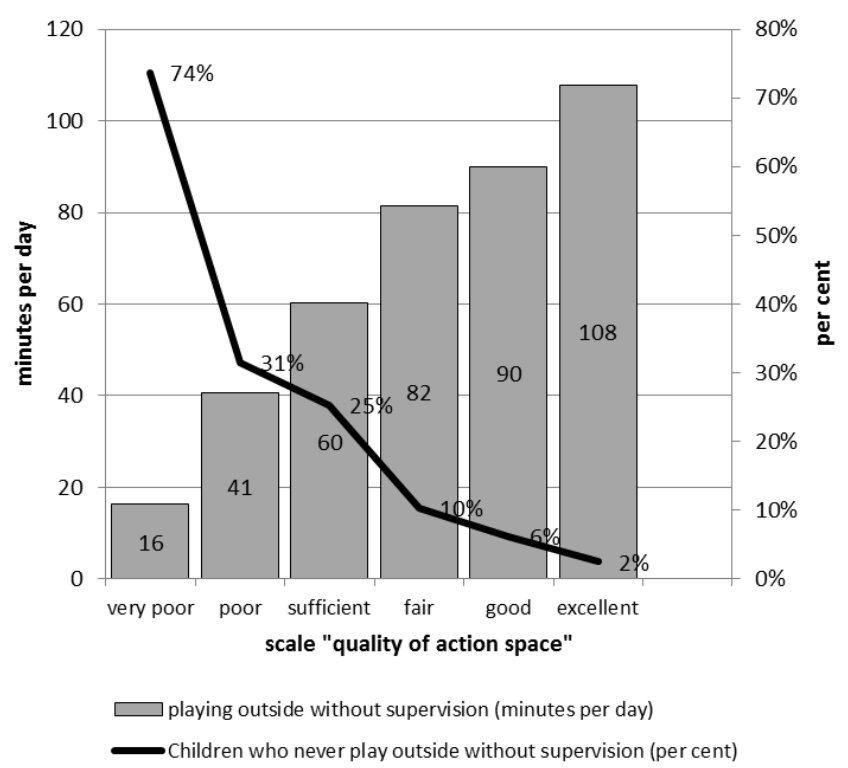

$\mathrm{r}_{\mathrm{S}}=0,549 ; \mathrm{n}=3808$ children

Figure 1. Playing outside without supervision and quality of action space.

Overall, of the more than 5,000 children studied, 55\% play outside without adult supervision, but there are striking variations between neighbourhoods. Results show clearly that the quality of action space is the most important determinant of children's daily routines. For example, if the environment is favourable for children then they play on average nearly two hours a day outside their home without supervision. Where the outdoor conditions are bad for children, the average time for this important activity is reduced to less than 15 minutes a day.

This diagram, (figure 1) shows that $74 \%$ of children in very poor quality areas are not allowed to play outside unsupervised, compared to areas that have excellent action space, where only $2 \%$ of children are not allowed to play outside without adult supervision.

These important results can be summarised by identifying two types of childhood: One type can be called "autonomous childhood" and the other "heteronomous childhood". "Autonomous childhood" means that children often play outside their home without supervision for long periods of time, that they seldom are looked after in a child care facility in the afternoon and they often participate in extracurricular activities, such as sports, clubs or music. Heteronomous childhood provides little or no opportunity for children to act independently and describes children rarely having opportunities to play outside without adult supervision, often being in organised child care after school, and with little or 
no participation in extracurricular activities.

$$
\text { Determinants for autonomous / heteronomous }
$$
childhood

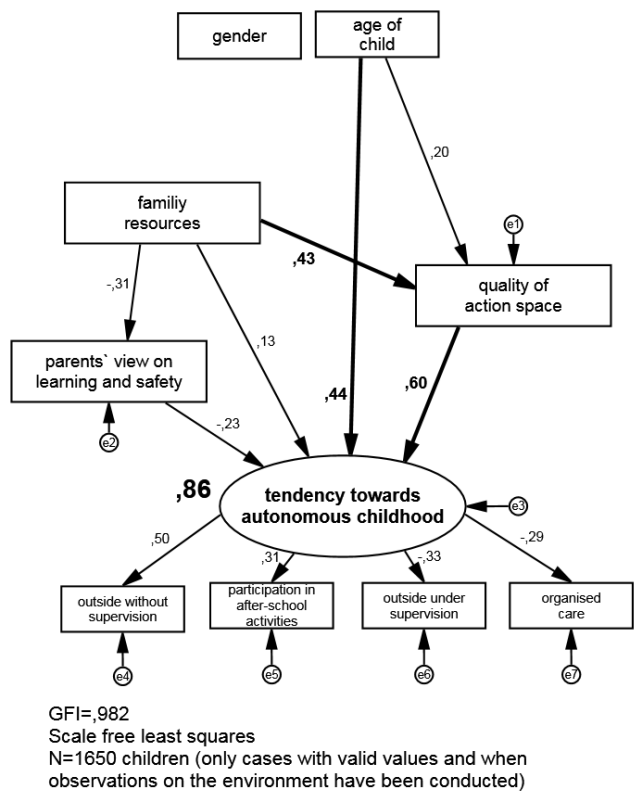

Figure 2. Structural model "autonomous childhood".

The result of a multivariate analysis - a structural model shows how different conditions influence the tendency to "autonomous" and "heteronomous childhood" (fig. 2). 13 This model explains $86 \%$ of the variance of this tendency.

The extent of "autonomous childhood" varies not only with children's ages but also and very clearly with the conditions of the environment around their homes, i.e. with the quality of their action space. Furthermore, it is striking that action space quality varies according to the resources of the family, with the result that there is a form of multiple disadvantaging: Children from families with less economic resources and cultural capital not only have a higher likelihood of problems in their school careers associated with deprivation, but in addition, because of the social segregation in cities, they are less likely to live in home environments which allow free and unsupervised play. In the past "street childhood" was typical for children from socio-economically disadvantaged backgrounds, but under current conditions of city development "street childhood" is now more typical for children of wealthy, middle-class parents.

Stereotypes have formed of middle-class parents who schedule their children's lives with extracurricular activities. While this approach to parenting is obviously well-intended and may be driven by ambition, it has been critiqued as causing excessive pressure for these children and failing to

13 In a structural model each arrow represents the assumption about a causal influence. The numbers on the arrows are standardized regression coefficients. The method used for the model analysis is the LISREL-algorithm which is a combination of factor analysis and path analysis. GFI is a chi-square based "Goodness-of-Fit-Index" and should be near 1.00. The calculations have been performed by AMOS. allow them time for the vital activity of unstructured, free play.14 The Raum für Kinderspiel research shows that this stereotype is inaccurate: It is false to presume that children who attend extracurricular activities lack time and opportunities for free play. On the contrary, the correlation between family resources and educational background indicates that children who benefit from participating in after school sports, clubs, creative projects, music classes and so on, are also the children who live in places where they are most able to play freely, without adult supervision, out of doors. Furthermore, these tend also to be predominantly the families in which parents value outside play, unstructured by adults, as beneficial for children and therefore to be encouraged and facilitated.

\section{Recommendations}

The five local councils which participated in this research have each received detailed reports including recommendations for their areas, which they are now seeking to implement for the direct benefit of the children resident in those towns and neighbourhoods. These include specific proposals to reduce traffic risks and 'social danger,' to improve accessibility and to transform boring, under-used playgrounds into attractive sites for children with high utility values.

Even some of the most expensive modern conventional playgrounds with set pieces of play equipment, do not meet the requirements of child friendly play space, as they lack adaptability and have little or no scope for creativity. The length of time for which children are typically happily entertained by standard playground installations is limited, because children soon explore all of the options available. The former head of playground safety at the Royal Society for the Prevention of Accidents is quoted as saying "We have made playgrounds so monumentally boring that any self respecting child will go somewhere else to play - somewhere more interesting and usually more dangerous.... The value in them is so limited that it barely scores on any assessment of play value." 15

Following on from the pioneering work in the German city of Freiburg in the 1990s, 16 the local council has continued seeking to facilitate high quality space for children in residential areas. Children have been consulted on what they see as desirable public space in which to play and residents of all ages have been involved in physically implementing the agreed renovations.

Traditional playground installations, such as spring seatrockers, see-saws, climbing frames and swings have been removed and replaced with mounds and dips created in varied forms, on the instructions of local children. Bushes and fast growing shrubs have been planted and, where

14 Conservative Party Childhood Review More Ball Games (undated) Page 6 http://www.actoea.org.au/wp-content/uploads/2012/01/childhood-review.pdf 15 Gleave 2008, page 15, quoting Ball, D. in Thom, B., Sales, R., Pearce, J., (eds) Growing up with Risk Bristol, Policy Press.

16 Blinkert 1993; 2005. 
possible, running water has been provided. Informal and irregular wooden, stone and other shapes have been included, along with a variety of surface materials such as sand, earth and mud. Play spaces of this kind have been so popular in some areas of Freiburg that they have attracted children in far greater numbers, and for much longer periods of time, than the previous forms of standard playground.

The cost of building such play spaces has been estimated by Freiburg City Council as 50\% less than the cost of building conventional playgrounds, while the maintenance costs are about the same.

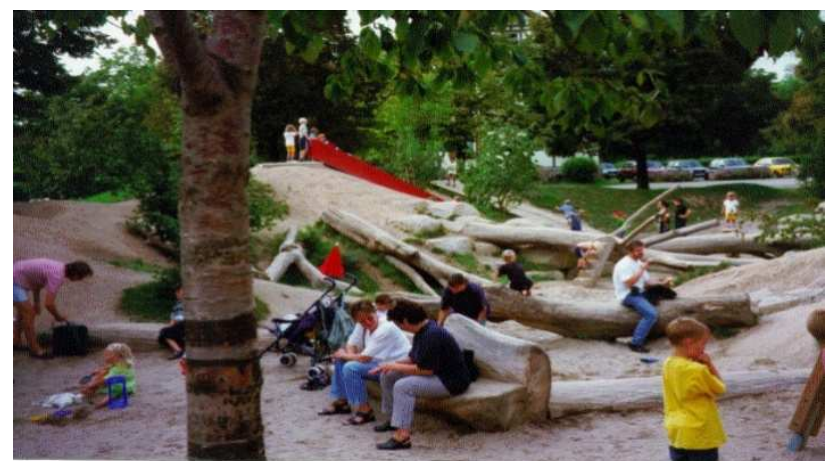

Figure 3. A transformed playground in Freiburg

The involvement of children in planning and making improvements to their neighbourhoods is not only in compliance with the right of children to have their voices heard in decisions affecting them, as set out in Article 12 UNCRC, but also constitutes basic pragmatism: where local children have taken part in designing and building their play spaces there is a far greater likelihood of the area actually meeting children's needs and achieving its basic purpose of having high play value. 17

Problems of vandalism and damage are likely to be significantly reduced in this form of play space: Firstly the 'installations' are intended to be adaptable and used by children in whatever way they find fun and challenging. Thus, branches which are broken off will be from varieties of bushes that are fast growing and will soon regenerate all the more thickly. If teenagers entertain themselves in the play area by perhaps digging a large hole, damming the stream or even lighting a fire in the evening, the result may be all the more interesting for younger children to explore the next day, without the play space having been destroyed. Secondly, an area which residents have been involved in creating and which they see local children enjoying in large numbers is at lower risk of being wrecked due to a strong sense of community ownership of and pride in the space. 18

In addition to the physical attributes of a play space, these

17 Shackell et al. p.27.

18 Ibid p. 138, citing example of transformation of Spa Fields Play Space, Islington, London, where the play space "has restored a sense of safety to this site - which had latterly become a no go area. There has been no vandalism or antisocial behaviour on the site since completion." Contrast Langden Park (page 130) where it was thought that greater community involvement might have reduced vandalism. recent German research findings confirm that there are social requirements for a space to be child friendly, although the attributes of an area that feels safe and friendly are also the requirements for the rest of the population to be able to enjoy public spaces in residential areas. Tim Gill has argued that "communities and neighbourhoods that provide good play opportunities tend to be places that work well for everyone."19

Without being naive about the extent and depth of social dysfunction and deprivation in some inner city areas, many unattractive residential spaces have potential to be radically improved to the immediate and significant benefit of children. The very process of community consultation and team working to improve play space can amount to positive community development which improves the atmosphere and living conditions to the benefit of all residents. 20

Nevertheless, many causes of neighbourhoods becoming un-child-friendly relate to regional or national government policies and cannot be tackled by community associations. All of the departments and ministries with responsibility for policies which affect the quality of public space in residential areas need to take full account of the significance of play space for children, in accordance with their obligations under the UNCRC, and to avoid the long term social cost of raising children who suffer developmental deficits due to play deprivation.

Overall urban, traffic and housing design must be brought onto the child-policy agenda and vice versa: Children's policy should not be isolated as a social work issue: this research demonstrates that children's wellbeing must be mainstreamed into the remits of all those whose work affects public spaces, including traffic planners, police, urban designers, architects, public landscapers, gardeners and community workers. The study offers a test to assess the child-friendliness of residential environments. Furthermore, it is argued that it is not sufficient to build more playgrounds but rather that child-friendliness must be a guiding principle for all aspects of urban planning, beyond just residential areas.

\section{Implications of Findings from This Research}

A motivation for the Raum für Kinderspiel! research project was a concern that the opportunities for children in Germany to play freely, out of doors without adult supervision have diminished in recent years. In global terms German social circumstances and policies have a great deal in common with other industrialised, western countries, especially European States. There have been enormous changes in children's lives in all of these regions by comparison with the previous two generations, which may be attributed to multiple factors, including increase in traffic, urbanisation, fear of violence and child abduction, academic

19 Gill 2014, p. 32.

20 Shackell et al. p. 118, Cutsyke Play Forest, Castleford, West Yorkshire. 
pressure on children and electronic entertainment.

The premise of the Raum für Kinderspiel! research project, that play is necessary for healthy child development, is internationally agreed and the need for children to play is recognised as of sufficient significance as to constitute a right under international law. However, the definition of play adopted in this study is less likely to be broadly accepted. The German researchers who devised and conducted Raum für Kinderspiel! take the view that the appropriate form of play to enable essential growth of autonomy in children aged 5 - 9 is outdoor play unsupervised by adults. In many countries this will be seen as controversial on grounds of safety, with the requirement for adult supervision of children under the aged of 10 being regarded as absolutely essential in some Western cultures, the USA being one of the most extreme examples.

Illustrative of the gulf between these views as to what constitutes appropriate play opportunities for children in this age group, is a case due to be considered by the Illinois Appellate Court in which a mother allowed her children aged 11,9 and 5, along with their 9 year old cousin, to play for half an hour in a park opposite her home, within her sight. The mother had expressly entrusted her oldest child to take care of the younger ones, but nevertheless she also checked on the children herself, by looking from her window every 10 minutes. None of the children came to any harm but a report was made to the Department of Child and Family Services by a passerby, as a result of which the mother has been found guilty of 'inadequate supervision' - defined as having left her children "without supervision for an unreasonable period of time without regard for the mental or physical health, safety or welfare of the minor."21 Far from being an exceptional case, this is indicative of the legal position and culture in the USA. Furthermore, the Family Defense Centre in Chicago, which represented this mother, states that their clients in such cases are very disproportionately single parents, immigrants and/or from ethnic minorities, which raises serious questions of equality and discrimination in enforcement of so-called 'child protection.'

However, there is no monopoly of opinion on this issue in the USA: Some of those who disagree with what they see as an overcautious and harmful culture in respect of children's safety are making strenuous efforts to assert the right of children to free play and independence. Advocates of the importance of free play and 'free range childhood' argue that greater harm is done to children who are denied access to opportunities to develop their autonomy, when compared to the actually minimal scale of risk of them coming to serious physical harm because they are out of adult supervision.22 Cases have been successfully appealed, for example overturning a finding of neglect which had been made against parents for allowing their children, aged 9 and 6 to

21 http://www.familydefensecenter.net/client-stories/mother-challenges-dcfsdecision-that-prevents-her-three-children-from-playing-outside/ 22 Frost 2006, Brussoni et al. 2012, http://www.freerangekids.com. walk a mile home together from a park. 23

The profoundly different approaches to child development and safety which are commonplace in the USA, as described above, leave little scope for meaningful application of the Raum für Kinderspiel! research findings to societies such as parts of the USA where parents may be prosecuted for allowing children in the age group studied to play outside in public spaces without constant adult supervision. However, it is submitted that the research is relevant to such situations, in that it provides firm evidence that children as young as 5 can and do play safely outdoors without adult supervision in urban settings. However, a massive range of other social factors come into play, not least the scale of gun ownership and violence in the USA, making comparisons complex and challenging.

A central finding of Raum für Kinderspiel! is that the quality of their residential neighbourhoods is the key factor affecting the extent to which children play outside without adults, and that this correlates with family resources: Children whose parents have more education and resources play outside on their own more because they live in areas where there is suitable space for them to do so.

Given the evidence already available showing the extent of reduction in children's opportunities to play freely outside, 24 it is arguable that these research findings are highly relevant to the UK. The central finding that deprivation exacerbates reduction in outdoor play, accords with the findings of several studies conducted in the UK, which establish correlation between poverty and neighbourhoods with poor quality outdoor space limiting children's free play opportunities. 25 However, other research in England has concluded that parental fears were a greater factor than residential or outdoor circumstances in limiting children's play opportunities. 26

The changing nature of childhood has been the subject of widespread debate in the UK.27 Numerous articles, in both news and academic media, have contrasted children's current lifestyles with the childhood experiences of their parents and grandparents, in particular with regard to contact with nature. 28 Apart from concern at children's lack of basic knowledge of their natural environment, 29 there is widespread consensus that harm is being done to children's development through restrictions on their experiences and independent activities. 30

Several writers have pointed out that parental fears are often wildly out of proportion to the statistical, factual level of danger: child abduction is extremely rare; far more

\footnotetext{
23 'Maryland's free range parents cleared of neglect in one case,' Washington Post, $25^{\text {th }}$ May 2015.

24 Play England Literature Review 2011

25 Nairn and Ormrod 2007 p.6.

26 Valentine and McKendrick 1997.

27 Play England Literature Review 2011.

28 See, for example, Natural England 2009.

29 http://www.nationaltrust.org.uk/article-1356398668159/

30 For example Young 2010, Play England Literature Review 2011, Gleave 2008, Gill 2007 and 2011, Furedi 2008, Campbell 2011, Dillner 2015.
} 
children die in car accidents, yet car travel is a risk parents are generally prepared to take with their children's safety. 31 It appears that parents in the UK are faced with complex and contradictory information in their efforts to do what is best for their children: There is a culture of caution, fear and mistrust which means they feel obliged to accompany their children in public.32 A survey conducted for the Children's Society in 2006 found that 43 per cent of UK adults thought that children under the age of 14 should not be allowed out with their friends without adult supervision, while 22 percent of adults over the age of 60 considered that children should be over 16 before going out alone. 33 However, there is also evidence that parents generally recognise the benefits of free play and see the value to their children in being out in open spaces. 34

One explanation for play opportunities having become particularly restricted in the UK is that those responsible for play provision (parents, teachers, local authorities etc.,) fear that they may breach health and safety legislation and / or be sued if a child comes to harm while using space or equipment that they have provided.35 The extension, in 1974, of the health and safety legislation, which was originally designed primarily for the protection of factory workers, to public facilities, has arguably had extensive unforeseen negative consequences. Public disquiet has frequently been expressed over the application of health and safety regulations in ways which apparently do more harm than good. The concept of 'safety as paramount' has been allowed to outweigh other factors, to a sometimes irrational and unhelpful degree. 36

Such is the level of concern about children's diminished opportunities to learn to deal with risks that the Chair of the British Health and Safety Executive has stated "If we don't allow children to experience managed risk I have grave concerns about the future for workplace health and safety. If the next generation enter the workplace having been protected from all risk they will not be so much risk averse as completely risk naïve - creating an enormous task and dilemma for their employers..."37

The consequences of excessive risk aversion and overapplication of safety rules to both adults and children, alongside perceptions that a developing 'compensation culture' is having a negative impact, led to David Cameron establishing an enquiry on these issues as soon as he became

31 For example, Madge and Barker 2007, Living Streets 2009, Dillner 2015, Tremblay et al. 2015, Ball and Ball-King 2011

32 Living Streets 2009, Bailey 2008; Madge and Barker 2007.

33 http://www.childrenssociety.org.uk/news-and-blogs/press-release/childhoodfriendships-risk-reveals-new-survey

34 Play England Literature Review 2011, Furedi 2008.

35 Play England Literature Review 2011, Furedi 2008.

36 Dumfries school bans kids from playing with balls at break times" $21^{\text {st }}$ November 2014 http://www.dailyrecord.co.uk/news/local-news/dumfries-schoolbans-kids-playing-4668408 "a well-meaning head teacher decided children should wear safety goggles to play conkers." http://www.hse.gov.uk/myth/september.htm "A school briefly banned children from using cardboard egg boxes to make things ... They were concerned that children might catch salmonella." http:/www.hse.gov.uk/myth/august.html

37 Speech by Judith Hackitt CBE, 8 May 2008 http://www.hse.gov.uk/aboutus/speeches/transcripts/iosh080508.htm
Prime Minister. The resulting report38 makes only minor reference to children, but acknowledges that "this disproportionate approach [to health and safety] has also had a negative impact on education in this country and has decreased the number of opportunities available to children to experience risk."39

The Conservative Party Childhood Review report 'More Ball Games' was prepared in reaction to a 2007 UNICEF league table on the quality of children's lives in 21 developed countries, in which the was UK ranked last.40 Among the three policy aims produced by this Review is a commitment to "Making outdoor space safer and more protected, so that parents and children feel more confident about spending time there."

Indicative of the positive progress being made in the UK to address inequality in children's access to play space is that $£ 124$ million was committed by the Big Lottery to the Children's Play programme. This defined play as "...what children and young people do when they follow their own ideas and interests, in their own way, and for their own reasons" and the programme has been focussed on the most deprived areas. 41

A specific recommendation of the Young Report was for a "shift from a system of risk assessment to a system of riskbenefit assessment and consider reviewing the Health and Safety at Work etc Act 1974 to separate out play and leisure from workplace contexts." 42 This has been implemented following active lobbying by the Play Safety Forum 43 ('PSF') with the making of a High Level Statement by the Health and Safety Executive in July 2012 entitled 'Children's play and leisure: promoting a balanced approach.' A key message of this Statement is that 'Play is great for children's well-being and development. When planning and providing play opportunities, the goal is not to eliminate risk, but to weigh up the risks and benefits. No child will learn about risk if they are wrapped in cotton wool'.44

The PSF has subsequently published an authoritative and practical implementation guide on 'Managing Risk in Play Provision,' 45 which affirms the legitimacy and benefits of balancing children's need for learning opportunities in risk taking with seeking to provide for their physical safety. This is a highly significant step towards reversing the trend of play areas that are so secure and safe that children find them boring and they fail to provide children opportunities to develop essential life-skills.

The effects of actual likelihood of liability cannot readily be separated from the effects of widely-believed myths and

38 Young 2010.

39 Ibid p. 12.

40 UNICEF 2007.

41 Hall and Day 2009.

42 Young 2010, p. 37.

43 The Play Safety Forum an independent body hosted by Play England and includes a range of relevant experts, including representatives from Play Wales, Play Scotland and PlayBoard Northern Ireland. http://www.playengland.org.uk/playsafetyforum

$44 \mathrm{http}: / /$ www.hse.gov.uk/entertainment/childrens-play-july-2012.pdf 45 Ball, Gill \& Spiegal 2013 
misinformation about risk and liability for accidents. The Occupiers' Liability legislation and caselaw does allows for balance of foreseeable risk against social benefit or value, 46 and the Compensation Act 2006 constitutes a step in the right direction, creating a statutory requirement to balance benefit of foreseeable risk against safety in questions of liability for injury. However, the arguments for greater weight to be placed on the benefits of risk (particularly for children, but also for adults,) have not yet permeated the cautious approach of many local authorities and insurers, arguably because of the unpredictability of decisions in the lower courts.47 The momentum built up by the insurance industry, health and safety fears and lawyers who profit from claims cases, makes it unsurprising that this one legislative change has not immediately achieved a significant impact in changing attitudes. However, it is arguable that the considerable successes of the UK wide Children's Play programme, and its achievements in assuaging parental fears, based on risk - benefits assessments (rather than purely on risk assessments), along with the work of the Play Safety Forum, are positive signs of progress.

In the UK the definitions of child neglect and harm under child protection legislation vary between the jurisdictions, but are also generalised and open, leaving great scope for flexible or unclear interpretation. 48 The potential exists for children in the UK to be taken into care and for parents to be prosecuted, or at least monitored by social services, where parents allow their children to develop their autonomy in ways which are seen by others as excessively risky. However, despite the striking changes in recent years in social norms on age appropriate independence, it is to the credit of child care authorities across the UK that there has been no plethora of prosecutions or child protection proceedings, such as in the USA. This is not to suggest that there is no pressure on parents in the UK, 49 nor that issue should be ignored - far from it (see section 7 below), but rather to assert that legal proceedings would be an appallingly blunt, expensive, slow and inappropriate method of creating social policy on an issue as controversial and urgent as this.

Clearly, a significant proportion of the world's children lack resources to meet other fundamental needs as well as the right to play, such as the right to adequate nutrition, clean water, safe housing, medical care, formal education and freedom from race, gender and disability discrimination. For these children the quality of play space may not be the first priority in seeking to improve their circumstances. However, account should be taken of the real consequences of play deprivation: or to express this positively: children whose right to play is effectively implemented may thereby

46 Tomlinson -v- Congleton Borough Council and Others, [2003] UKHL 47. 47 Ball and Ball-King 2011, p. 76.

48 Section 31 of the Children Act 1989 (England and Wales), Part 1 of the Children (Scotland) Act 1995, Articles 2 and 50 of the Children (Northern Ireland) Order 1995.

49 Furedi 2008, p 5. develop life-skills which enhance their capacity to cope with the challenges and deficits in other aspects of their lives.

Furthermore, as increasing proportion of the world's population seeks to emulate western social and material models, it is crucial that we communicate widely on our experiences and the problems caused by industrialisation. Given that some of the solutions proposed are not costly, it may well be practical and significantly worthwhile for developing countries to take account of the long term impact which play deprivation may have on their forthcoming generations if previous models of urbanisation are followed.

\section{Conclusions and Proposals for Future Research}

Because of the significance of free play in enabling fundamental aspects of child development, and in the light of this new evidence that living environments impact directly on opportunities for independent outdoor play, the improvement in child friendly design of urban and residential outdoor space is an urgent equality issue with profound implications for children's health and life chances. The quality of the public space in residential areas has been shown to affect the quality of childhood and this, in turn, impacts on child development and resulting life chances. Children from socially and economically deprived families are less likely to have access to safe, suitable space in which to play freely, and are thereby less able to exercise their right to play. The right to play has been enshrined in international law, and a UN General Comment issued on the specific point, not because it is merely nice for children to play, but because play is essential to healthy development of basic physical, cognitive and social competences.

Germany is an extremely wealthy country in global terms, and Baden-Württemberg is an affluent region of Germany, However, even here, children from poorer families are suffering from inequality due to the failure of public authorities to meet their needs for public, appropriate play space. This is a form of age-discrimination in that the particular but crucial needs of their age group are not met: Just as public facilities must meet the needs of wheelchair users and the elderly, public areas where children are housed should be suited to their need for opportunities to play safely, without adult supervision.

Some of the potential remedies to this problem are relatively low cost and ought therefore to be readily implemented by local authorities. When compared to the costs of playgrounds with rigid, limited equipment, such as slides and soft surfaces which have been built with good intention, it is relatively cheap to provide creative, flexible, natural environments which are far more suited to children's needs. The experience of the work done towards this aim in Freiburg indicates that this is likely to be all the more successful when implemented with children themselves and 
their families.

No calculation has, as yet, been made of the cost of not meeting children's needs for appropriate play-space, although it is all too apparent that the resulting longterm 'costs' to society go beyond merely financial significance, due to the profoundly negative individual consequences of play deprivation. If children having fun is not, per se, seen as a sufficient priority for investment by austerity-stretched public budgets, we ought to ensure that children have good play space because this will be much simpler and cheaper to achieve than the alternative of having to dealing with the consequences if we do not.

The reasons behind the contrasting childhood experiences in otherwise relatively similar countries, controlled by the same European play equipment safety standards, warrant further investigation: Why are parents in the UK more anxious and unwilling to allow their children out to play, compared to parents in other parts of Europe? Why has fear of injury and strangers as a threat to children's safety escalated more in the UK than, for example, in Germany? Are children actually in more danger? If so, is this to some extent due to a lack of opportunities to develop relevant skills and autonomy?

A complex challenge arises in distinguishing between the impact of changing attitudes on law, as opposed to the reverse effect - the impact of law in changing attitudes. The role of the insurance industry and the health and safety anxieties, as described above, exacerbate the detrimental impact of litigation fears in impeding children's freedoms. Research is needed to establish whether actual or feared liability in the event of injury is a significant factor that has caused impaired children's freedoms and play opportunities in the UK by comparison with their European counterparts: Are common law legal systems are more prone to these unintended consequences than civil law systems, due to the impact of changing social norms in developing caselaw, which do not have the same impact on codified legal systems? If so, what remedial legislation and other policy measures could effectively reverse the damaging trend towards play deprivation.

We plan and propose research in an international context to compare children's play opportunities and experiences in selected countries. In these investigations three groups of hypotheses will be tested:

Spatial impacts: Opportunities for children to play freely depend on spatial conditions in the environment near to their homes, which can be influenced by city planning. The aim is to formulate ideas for urban design which enable healthy child development.

Impact of law: The hypothesis to be tested is that liability (and / or a misplaced fear of liability) has inhibited free play outside of the home and risk taking activity by children in common law jurisdictions to a greater extent than in civil law jurisdictions.

Cultural impact: We assume that the influence of spatial conditions and the impact of law are mediated by cultural patterns. The research will identify the extent to which cultural differences between the participating countries affect the fulfilment of children's developmental potential, with specific reference to views on public space for children, expectations of personal and public safety, attitudes towards fostering children's independence, child protection and the importance which is placed on children's access to free outdoor play.

\section{References}

[1] Bailey, S. (2008): What and who it is that we don't trust? Joseph Rowntree Foundation.

[2] Ball, D. (2002): Playgrounds - risks, benefits and choices, HSE, 2002.

[3] Ball, D., Ball-King, L., (2011): Public Safety and Risk Assessment, Earthscan Routledge.

[4] Ball, D., Gill, T., Spiegal, B. (2012) Managing Risk in Play Provision, Play England for the Play Safety Forum.

[5] Blinkert, B. (1993): Aktionsräume von Kindern in der Stadt, Pfaffenweiler.

[6] Blinkert, B., Höfflin, P., Schmider, A.,Spiegel, J. (2014): Raum für Kinderspiel!, Berlin.

[7] Blinkert, B. (2005): Quality of the City for Children: Chaos and Order, in: Children, Youth and Environments 14(2), 99112.

[8] Bradshaw, J., Hoelscher, P., Richardson, D. (2007): An Index of Child Well-being in the European Union, Social Indicators Research (2007) 80: 133 - 177.

[9] Brussoni, M., Olsen, L., Pike, I., Sleet, D. (2012): Risky Play and Children's Safety: Balancing Priorities for Optimal Child Development, International Journal of Environmental Research and Public Health, 3134-3148.

[10] Campbell, D. (2011): Children growing weaker as computers replace outdoor activity, Guardian 21.5.11.

[11] Child Poverty Action Group (2009): Child wellbeing and child poverty: Where the UK stands in the European table.

[12] Conservative Party Childhood Review (2008): More Ball Games.

[13] Dillner, L., (2015): Should I let my child take more risks? Health Dilemmas. Observer, Guardian 14.6.15

[14] Frost, J.L. (2006): The Dissolution of Children's Outdoor Play: Causes and Consequences, University of Texas.

[15] Furedi, F. (2008): Paranoid Parenting.

[16] Gill, T. (2007): No Fear: Growing up in a risk averse society. London: Calouste Gulbenkian Foundation.

[17] Gill, T. (2011): The end of zero risk in childhood? Guardian 3.7.11.

[18] Gill, T. (2014): Play Return: A Review of the wider impact of play initiatives, Play England.

[19] Gleave, J. (2008): Risk and play: a literature review, Playday. 
[20] Gleave, J. (2010): Community play: a literature review, Playday.

[21] Graf, C. Dordel S. Koch B. Predel H-G: Bewegungsmangel und Übergewicht bei Kindern und Jugendlichen. In: DEUTSCHE ZEITSCHRIFT FÜR SPORTMEDIZIN, Jahrgang 57, Nr. 9 (2006).

[22] Hall, N., Day, L. (2009): Evaluation of Children's Play Programme, Report to Big Lottery Fund.

[23] Health and Safety Executive, (2012): Children's Play and Leisure: Promoting a Balanced Approach.

[24] Hüttenmoser, M. Degen-Zimmermann D. (1997): Lebensräume für Kinder. Empirische Untersuchungen zur Bedeutung des Wohnumfeldes für den Alltag und die Entwicklung von Kindern. Könitz.

[25] Karsten, L. (2005): It all used to be better? Different generations on continuity and change in urban children's daily use of space, Children's Geographies, 3:3, 275-290, DOI: $10.1080 / 14733280500352912$.

[26] Lester, S., Russell, W. (2010): Children's right to play: An examination of the importance of play in the lives of children worldwide, Bernard Leer Foundation.

[27] Living Streets (2009): No ball games here (or shopping, laying or talking to the neighbours.) How UK streets have become no-go areas for our communities. Living Streets.

[28] Louv, R. (2008): Last Child in the Woods: Saving our Children from Nature Deficit Disorder.

[29] Madge, N., Barker, J. (2007): Risk and Childhood, The Royal Society for the Encouragement of Arts, Manufactures \& Commerce, Risk Commission.

[30] Moss, S. (2012): Natural Childhood, National Trust.

[31] Nairn, A., Ormrod, J. (2007): Watching, Wanting and Wellbeing: Exploring the Links, National Consumer Council.

[32] Natural England, (2009): Childhood and Nature: a survey on changing relationships with nature across generations.

[33] Olk, Th; Hübenthal, M. (2011): Zweckfreie Kindheit. in: Wittmann, S.; Rauschenbach, Th.; Leu, H.R.: Kinder in Deutschland. Eine Bilanz empirischer Studien, Weinheim.

[34] Play England (2011): A world without play: A literature review on the effects of a lack of play on children's lives.

[35] Play England (2009): Playable Space Quality Assessment Tool, INSPIRE Consultancy.
[36] Renz-Polster, H., Hüther G. (2013): Wie Kinder heute wachsen. Weinheim/Basel.

[37] Rogers, S., Pelletier, C., Clark, A. (2009): Play and Outcomes for Children and Young People: Literature review to inform the national evaluation of Play Pathfinders and Play Builders, Department of Children, Schools and Families, DCSF-RBX09-06.

[38] Shackell, A., Butler, N., Doyle, P., Ball, D. (2008): Design for Play: A guide to creating successful play spaces, Play England

[39] Shaw, B., Watson, B., Frauendienst, B., Redecker, A., Jones, T. with Hillman, M. (2013): Children's independent mobility: a comparative study in England and Germany (1971 - 2010), London: Policy Studies Institute.

[40] Thomas, G., Thompson, G. (2004): A Child's Place: Why environment matters to children, Green Alliance/DEMOS.

[41] Tremblay et al. (2015): Position Statement on Active Outdoor Play, Int. J. Environ. Res. Public Health 2015, 12, 6475-6505; doi:10.3390/ijerph120606475

[42] UN Committee on the Rights of the Child General comment No. 17 (2013) (art. 31), 17 April 2013, CRC/C/GC/17.

[43] UN General Assembly, Convention on the Rights of the Child, 1989, United Nations, Treaty Series, vol. 1577.

[44] UNICEF (2007): Child poverty in perspective: An overview of child well-being in rich countries, Innocenti Report Card 7, UNICEF Innocenti Research Centre, Florence.

[45] UNICEF (2013): Child Well-Being in Rich Countries: A Comparative Overview, Innocenti Report Card 11, UNICEF Innocenti Research Centre, Florence.

[46] Valentine, G., McKendrick, J. (1997): Children's Outdoor Play: Exploring Parental Concerns About Children's Safety and the Changing Nature of Childhood, Geoforum Vol, 28, No 2, 219-235 1997.

[47] Young (2010): Common Sense Common Safety, The Young Report, Cabinet Office, H.M.Government, 2010.

[48] Zeiher, H. (1990): Organisation des Lebensraums bei Großstadtkindern - Einheitlichkeit oder Verinselung? In: L. Herlyn U. Bertel (Hg.): Lebenslauf und Raumerfahrung. Opladen, S. 35-57.

[49] Zinnecker, J. (1990): Vom Straßenkind zum verhäuslichten Kind, in I.Behnken (Hg.),Stadtgesellschaft und Kindheit im Prozeß der Zivilisation, Opladen. 